\title{
Bioreactivity of Stent Material: In Vitro Impact of New Twinning-Induced Plasticity Steel on Platelet Activation
}

\section{Carole Verhaegen1, Sophie Lepropre', Marie Octave1, Davide Brusa ${ }^{2}$, Luc Bertrand, Christophe Beauloye ${ }^{1,3}$, Pascal J. Jacques ${ }^{4}$, Joelle Kefer1,3, Sandrine Horman1*}

${ }^{1}$ Pôle de Recherche Cardiovasculaire, Université catholique de Louvain (UCLouvain), Brussels, Belgium

${ }^{2}$ Plateforme de Cytométrie de Flux, Université catholique de Louvain (UCLouvain), Brussels, Belgium

${ }^{3}$ Division of Cardiology, Cliniques Universitaires Saint-Luc, Université catholique de Louvain (UCLouvain), Brussels, Belgium

${ }^{4}$ Department of Materials and Process Engineering, Institute of Mechanics, Materials and Civil Engineering, Université catholique de Louvain (UCLouvain), Brussels, Belgium

Email: *sandrine.horman@uclouvain.be

How to cite this paper: Verhaegen, C., Lepropre, S., Octave, M., Brusa, D., Bertrand, L., Beauloye, C., Jacques, P.J., Kefer, J. and Horman, S. (2019) Bioreactivity of Stent Material: In Vitro Impact of New Twinning-Induced Plasticity Steel on Platelet Activation. Journal of Biomaterials and $\mathrm{Na}$ nobiotechnology, 10, 175-189.

https://doi.org/10.4236/jbnb.2019.104010

Received: July 1, 2019

Accepted: September 17, 2019

Published: September 20, 2019

Copyright $\odot 2019$ by author(s) and Scientific Research Publishing Inc. This work is licensed under the Creative Commons Attribution International License (CC BY 4.0).

http://creativecommons.org/licenses/by/4.0/

\begin{abstract}
A current challenge concerns developing new bioresorbable stents that combine optimal mechanical properties and biodegradation rates with limited thrombogenicity. In this context, twinning-induced plasticity (TWIP) steels are good material candidates. In this work, the hemocompatibility of a new TWIP steel was studied in vitro via hemolysis and platelet activation assessments. Cobalt chromium (CoCr) L605 alloy, pure iron (Fe), and magnesium (Mg) WE43 alloy were similarly studied for comparison. No hemolysis was induced by TWIP steel, pure Fe, or L605 alloy. Moreover, L605 alloy did not affect $\mathrm{CD} 62 \mathrm{P}$ exposure, $\alpha \mathrm{IIb} \beta 3$ activation at the platelet surface, or phosphorylation of protein kinase $\mathrm{C}$ (PKC) substrates upon thrombin stimulation. In contrast, TWIP steel and pure Fe significantly decreased platelet response to the agonist. Given that similar inhibitory effects were obtained when using a conditioned medium previously incubated with TWIP steel, we postulated TWIP steel corrosion to be likely to release components counteracting platelet activation. We showed that the main ion form present in the conditioned medium is $\mathrm{Fe}^{3+}$. In conclusion, TWIP steel resorbable scaffold displays anti-thrombogenic properties in vitro, which suggests that it could be a promising platform for next-generation stent technologies.
\end{abstract}

\section{Keywords}

Stent, TWIP Steel, Platelet, Biomaterial, Hemocompatibility 


\section{Introduction}

Endothelial dysfunction due to dyslipidemia, hypertension or pro-inflammatory molecules leads to atherosclerotic plaques formation inside the vessel's intima layer which may cause coronary artery disease (CAD) [1] [2]. CAD, primarily responsible for myocardial infarction, is currently the first mortality cause worldwide [3] [4]. Coronary angioplasty with stent implantation is one of the most frequently performed therapeutic interventions to treat symptomatic CAD [5]. Stents are tubular scaffolds that are placed and expanded inside the coronary artery, designed to restore normal blood flow by local relief of obstructive lesions. However, harmful events, such as exacerbated smooth muscle cell proliferation in the neointima, chronic inflammatory local reactions, and thrombogenicity, contribute to lumen re-narrowing [6]. The mechanical characteristics, as well as the hemocompatibility of blood-contacting materials, must thus be investigated before considering them appropriate for in vivo applicability [7].

Blood flow through artificial stent-provided surfaces causes hemodynamic stress that may lead to erythrocytes rupture, called hemolysis [8], with associated consequences, including a reduction in oxygen transport to tissues, as well as free hemoglobin toxicity, notably altering kidney function [9]. In addition, the biomaterial exposure to the blood promotes the rapid adsorption of plasma proteins, including fibrinogen or von Willebrand factor, which both interact with the $\alpha \operatorname{IIb} \beta 3$ platelet integrin receptor, inducing platelet activation [7]. Stable integrin-dependent platelet adhesion leads to further platelet activation, with subsequent release from their granules ( $\alpha$-, dense, and lysosomal) of a broad range of biomolecules that act in both autocrine and paracrine ways to amplify the activation process [10]. Moreover, degranulation alters platelet plasma membrane composition and results in surface exposure of P-selectin (CD62P), a protein involved in the interaction of platelets with endothelial cells and leukocytes [11]. Finally, the artificial stent-provided surfaces can activate the intrinsic coagulation pathway, thereby leading to thrombin generation [7]. Thrombin is not only a potent platelet agonist but also cleaves fibrinogen into fibrin, which accumulates on the biomaterial surface, being recognized as a late stent thrombosis feature [12] [13]. Importantly, platelets and the entire coagulation system have been considered as processes that all interact in multifaceted ways [14]. Altogether, this indicates that platelet activation is undoubtedly an essential part of hemocompatibility testing [7].

Until recently, stent technology was based on using permanent bare metal stents (BMS). Cobalt-chromium ( $\mathrm{CoCr}$ ) has so far been considered to be the backbone of several stent generations [6]. However, the permanent delivery of a metallic implant has been demonstrated to be associated with several drawbacks, including vessel caging, vasomotion impairment, late stent thrombosis, and nonpermissive characteristics for later surgical revascularization [15] [16]. Given that a stent's scaffolding effect must only persist for 6 - 12 months, i.e. the time required to achieve arterial remodeling, the development of bioresorbable stents 
is a promising approach enabling these limitations to be overcome [17]. Polylactic acid bioresorbable scaffolds failed to demonstrate a better outcome than conventional metallic permanent stents, combining a poor radial force and a higher delayed thrombogenicity. In contrast, iron $(\mathrm{Fe})$ and magnesium $(\mathrm{Mg})$ alloys were reported to be suitable metals for bioresorbable stents in terms of undesirable effects [18] [19] [20] [21] [22]. Pure Fe stent implantation in animals was shown to be associated with good biocompatibility [23] [24] [25]. Mg-based stent has shown a good safety profile in patients [26]. While stents based on some $\mathrm{Fe}$ alloys present mechanical properties comparable to those of $\mathrm{CoCr}$ alloy, $\mathrm{Mg}$ alloy stents suffer from lower mechanical properties [27]. Moreover, Fe and $\mathrm{Mg}$ alloys were reported to be associated with an uncontrollable degradation rate [19] [28]. This highlights the need to further pursue investigations in this field, with the aim to modify or better control the degradation rate, particularly by optimizing the chemical compositions of the alloys.

Amongst the Fe-based alloys for bioresorbable stenting solutions, Fe-Mn alloys were so far considered based on their improved mechanical properties [18]. Some of them constitute twinning-induced plasticity (TWIP) steels [29] [30] [31]. The present in vitro study sought to characterize the impact of new TWIP steel composed of $\mathrm{Fe}, \mathrm{Mn}, \mathrm{C}$ with minor additions of $\mathrm{Si}$, and $\mathrm{Al}$ on hemolysis and platelet activation. CoCr L605 alloy and Mg WE43 alloy, and pure Fe were tested for comparison.

\section{Materials and Methods}

\subsection{Scaffolds Preparation}

In this work, TWIP steel (73.5 wt.\% Fe, 24 wt.\% Mn, 0.4 wt.\% C, 1 wt.\% Al, 1 wt.\% Si) was compared with CoCr L605 alloy (65 wt.\% Co, 27.5 wt.\% Cr, 6.2 wt.\% Mo and minor additions ( $<0.5$ wt.\%) of $\mathrm{Fe}, \mathrm{Mn}, \mathrm{Ni}$ and $\mathrm{Si}$ ), $99.99 \%$ pure $\mathrm{Fe}$, and Mg WE43 alloy (93 wt.\% Mg, 4 wt.\% Y, 0.5 wt.\% Gd, 2 wt.\% Nd, 0.5 wt.\% Dy, 0.5 wt.\% Zr). Ingot of TWIP steel was first cast after induction melting of the different pure elements (provided by Goodfellow) added in the right proportion. This ingot was then reheated to $1250^{\circ} \mathrm{C}$ for $30 \mathrm{~min}$ before being hot rolled. The same procedure was applied for pure Fe ingot. CoCr L605 alloy was provided by Biotronik. Mg WE43 alloy was provided by Magnesium Elektron. All metallic samples were cut into rectangular specimens of $1 \mathrm{~mm} \times 4 \mathrm{~mm} \times 10$ $\mathrm{mm}$. For surface preparation, the TWIP steel and pure Fe specimens were chemically etched in a solution of HF2.9M and $\mathrm{H}_{2} \mathrm{O}_{2} 4.3 \mathrm{M}$ for 3 minutes (min) and rinsed in water. They were then electropolished at $20 \mathrm{~V}$ in a solution of $\mathrm{HClO}_{4} 575 \mathrm{mM}$ and $\mathrm{CH}_{3} \mathrm{COOH} 16.6 \mathrm{M}$ for $1 \mathrm{~min}$. The L605 alloy was electropolished at $4 \mathrm{~V}$ in a solution of $\mathrm{H}_{3} \mathrm{PO}_{4} 11.6 \mathrm{M}$ for $6 \mathrm{~min}$. The WE43 alloy was electropolished at $15 \mathrm{~V}$ in a solution of $\mathrm{CH}_{3} \mathrm{OH} 20.6 \mathrm{M}, \mathrm{CH}_{3}\left(\mathrm{CH}_{2}\right)_{3} \mathrm{OCH}_{2} \mathrm{CH}_{2} \mathrm{OH}$ $1272 \mathrm{mM}, \mathrm{Cl}_{2} \mathrm{MgO}_{8} 83 \mathrm{mM}$, and $\mathrm{LiCl} 208 \mathrm{mM}$ for $2 \mathrm{~min}$. All metallic samples were rinsed in denatured $\mathrm{C}_{2} \mathrm{H}_{5} \mathrm{OH} 99 \%(\mathrm{v} / \mathrm{v})$, then dried and kept in a desiccator until use. 


\subsection{Determination of Blood Cell Number}

Whole blood was collected from healthy volunteers using a 21-gauge butterfly needle in a tube containing $1 / 10$ volume of citrated solution (citrate, phosphate, dextrose, and adenine). Metallic samples were immersed in whole blood at $37^{\circ} \mathrm{C}$ for 1 hour. The tubes were gently mixed every $10 \mathrm{~min}$ to avoid blood cell decantation. The numbers of platelets, white blood cells, and red blood cells were measured using Cell-DYN Emerald (Abbott Diagnostics), before and after incubation with the metallic samples.

\subsection{Hemolysis Assay}

Blood from healthy donors was collected using a 21-gauge butterfly needle in a tube containing $1 / 10$ volume of citrated solution, then diluted with normal saline at a volume ratio of 4:5. Five specimens of L605 alloy, TWIP steel, pure Fe, and WE43 alloy were dipped in $10 \mathrm{~mL}$ of normal saline for $30 \mathrm{~min}$ at $37^{\circ} \mathrm{C}$. Next, $200 \mu \mathrm{L}$ of diluted blood were added to the tubes containing the samples and incubated for $60 \mathrm{~min}$ at $37^{\circ} \mathrm{C}$. After the incubation time, the metallic samples were removed, and the blood was centrifuged at $800 \mathrm{~g}$ for $5 \mathrm{~min}$. The supernatant was transferred to a 96-well plate for spectroscopic analysis at $540 \mathrm{~nm}$ with Victor X4 (Perkin Elmer). An increase in optical density (OD) of the supernatant reflects hemoglobin release from red blood cells via hemolysis. Deionized water was employed as the positive control because its hypotonicity which induces complete hemolysis. Similarly, normal saline was set as the blank control because its isotonicity [9] [32]. The percentage of hemolysis was then calculated as the ratio of OD obtained with the test material with blank subtraction to OD obtained with the positive control with blank subtraction [33], as in Equation (1).

$$
\text { Hemolysis rate }=\frac{\text { OD of test }- \text { OD of blank control }}{\text { OD of positive control }- \text { OD of blank control }} \times 100
$$

\subsection{Platelet Isolation}

Venous blood from healthy volunteers was collected into tubes containing 1/10 volume of citrated solution using a 21-gauge butterfly needle. Platelet-rich plas$\mathrm{ma}(\mathrm{PRP})$ was obtained by centrifugation at $330 \mathrm{~g}$ for $20 \mathrm{~min}$ at $22^{\circ} \mathrm{C}$. For platelet activation measurement, platelets were isolated from PRP by centrifugation at $800 \mathrm{~g}$ for $10 \mathrm{~min}$, in the presence of eptifibatide $(4 \mu \mathrm{g} / \mathrm{mL})$ and apyrase $(1 \mathrm{U} / \mathrm{mL})$. The pellet was washed in modified Tyrode's buffer $(135 \mathrm{mM} \mathrm{NaCl}, 12 \mathrm{mM}$ $\mathrm{NaHCO}_{3}, 2.9 \mathrm{mM} \mathrm{KCl}, 0.3 \mathrm{Na}_{2} \mathrm{HPO}_{4}, 1 \mathrm{mM} \mathrm{MgCl}, 5 \mathrm{mM}$ D-glucose, $10 \mathrm{mM}$ Hepes, and $1.5 \% \mathrm{BSA}, \mathrm{pH} 7.4$, and $\left.37^{\circ} \mathrm{C}\right)$ containing eptifibatide $(4 \mu \mathrm{g} / \mathrm{mL})$ and apyrase $(1 \mathrm{U} / \mathrm{mL})$. The platelets were then isolated by centrifugation at $1000 \mathrm{~g}$ for $10 \mathrm{~min}$ at $22^{\circ} \mathrm{C}$ and re-suspended in modified Tyrode's buffer. The platelet concentration was measured by means of Cell-DYN Emerald (Abbott Diagnostics) and adjusted to $2.5 \times 10^{5}$ platelets $/ \mu \mathrm{L}$.

\subsection{Flow Cytometry Analysis}

For the $\mathrm{CD} 62 \mathrm{P}$ and $\alpha \mathrm{Ib} \beta 3$ analyses, washed platelets were treated for $60 \mathrm{~min}$ at 
$37^{\circ} \mathrm{C}$ with L605 alloy, TWIP steel, pure Fe, or WE43 alloy at a ratio of 1 metallic sample per $500 \mu \mathrm{L}$. After incubation, the metallic samples were removed, with the platelets counted using Cell-DYN Emerald (Abbott Diagnostics). Next, treated platelets $\left(6.25 \times 10^{6}\right)$ were incubated with PE mouse anti-human CD62P (BD Biosciences, \#555524) and FITC mouse PAC-1 antibody (BD Biosciences, \#340507) at saturating concentrations (1:12.5) for $15 \mathrm{~min}$ at room temperature. After adding $2 \mathrm{mM} \mathrm{CaCl}_{2}$, the platelets were stimulated with thrombin $(0.03,0.1$, or $0.3 \mathrm{U} / \mathrm{mL}$ ) for $2 \mathrm{~min}$ at $37^{\circ} \mathrm{C}$. To stop the reaction, they were fixed in $4 \%$ formaldehyde. The samples were analyzed using the BD Canto II flow cytometer, with 20,000 events recorded. For preparing the TWIP steel-conditioned medium, TWIP steel specimens were dipped in modified Tyrode's buffer for 1 hour at $37^{\circ} \mathrm{C}(1$ specimen $/ 1 \mathrm{~mL})$. The platelets were then re-suspended in the conditioned medium at a concentration of $2.5 \times 10^{5}$ platelets $/ \mu \mathrm{L}$. CD62P and PAC-1 quantification was done using flow cytometry after stimulation with thrombin $(0.03,0.1$, and $0.3 \mathrm{U} / \mathrm{mL})$, as described before. The results were compared with those obtained when the metallic samples were in direct contact with the platelets.

\subsection{Inductively Coupled Plasma and Colorimetric Tests}

Metallic specimens of TWIP steel were dipped into modified Tyrode's buffer for 1 hour at $37^{\circ} \mathrm{C}(1$ specimen $/ 1 \mathrm{ml})$, as previously described. The conditioned medium thus produced was collected immediately after incubation. The total Fe was measured in the conditioned medium by inductively coupled plasma (ICP). Moreover, colorimetric detection of $\mathrm{Fe}^{2+}$ and $\mathrm{Fe}^{3+}$ ions was performed in the conditioned medium using a spectrophotometer. The organic matter from the modified Tyrode's buffer reacted to create a trouble solution with $\mathrm{Fe}^{3+}$. Therefore, only $\mathrm{Fe}^{2+}$ was quantified and $\mathrm{Fe}^{3+}$ was deduced by subtracting the $\mathrm{Fe}^{2+}$ concentration from the total Fe concentration. Modified Tyrode's buffer with no metallic incubation was employed to set the blank.

\subsection{Western Blotting}

For the lysate preparation, platelets were centrifuged, and the pellet was lysed in SDS-Laemmli sample buffer $1 \times(25 \mathrm{mM}$ Tris-HCl, pH 6.8, 12.5\% (w/v) glycerol, 3\% $(\mathrm{w} / \mathrm{v})$ SDS, $0.01 \%(\mathrm{w} / \mathrm{v})$, bromophenol blue, and 6.25\% (v/v) $\beta$-mercaptoethanol). Whole platelet lysates were subjected to Western blotting. Antibody dilutions in 5\% BSA were 1:200,000 for the rabbit anti-phospho-PKC substrates antibody (Cell Signaling Technology, \#2261S) and 1:30,000 for the HRP-conjugated anti-rabbit antibody (Sigma-Aldrich, \#A0545). For the loading control, membranes were treated using azide $0.05 \%$, with the primary antibody being the rabbit anti-gelsolin antibody (Cell Signaling Technology, \#12953S) diluted 1:80,000 and the secondary antibody being the HRP-conjugated anti-rabbit antibody diluted 1:30,000. Band intensities were quantified using Image $\mathrm{J}$, and those obtained with the anti-phospho-PKC substrate antibody were normalized to those of the 
gelsolin loading control on the same gel.

\subsection{Statistical Analysis}

All experiments were performed in at least three independent replicates. Results were expressed as mean \pm SEM. The statistical analyses were conducted using a one-way or two-way analysis of variance (ANOVA), followed by Tukey's test for multiple comparison. $\mathrm{P}<0.05$ values were considered statistically significant. All statistical analyses were carried out using GraphPad Prism (GraphPad Software).

\section{Results and Discussion}

At first, we assessed the number of platelets, leukocytes, and erythrocytes after the blood had been in contact with the metals, in comparison with the blood not previously exposed to any metal. This was performed using the hematology analyzer Cell-DYN (Abbott Diagnostics). Platelet number (mean platelet count $\times$ $10^{5} / \mu \mathrm{L} \pm \mathrm{SEM}$ ) was $2.14 \pm 0.11$ before treatment, $2.13 \pm 0.10$ after 1 hour without metal, $2.12 \pm 0.11$ with L605 alloy, $2.10 \pm 0.10$ with TWIP steel, $2.07 \pm 0.11$ with pure Fe and $2.09 \pm 0.10$ with WE43 alloy. Leukocyte number (mean leukocyte count $\times 10^{3} / \mu \mathrm{L} \pm \mathrm{SEM}$ ) was $4.5 \pm 0.5$ before treatment, $4.4 \pm 0.5$ after 1 hour without metal, $4.4 \pm 0.6$ with L605 alloy, $4.4 \pm 0.6$ with TWIP steel, $4.3 \pm 0.6$ with pure Fe and $4.4 \pm 0.6$ with WE43 alloy. Erythrocyte number (mean erythrocyte count $\times 10^{6} / \mu \mathrm{L} \pm \mathrm{SEM}$ ) was $3.7 \pm 0.1$ before treatment, $3.5 \pm 0.1$ after 1 hour without metal, $3.4 \pm 0.3$ with L605 alloy, $3.6 \pm 0.1$ with TWIP steel, $3.5 \pm 0.3$ with pure Fe and $3.5 \pm 0.1$ with WE43 alloy. There was no change in blood cell number, indicating that the tested biomaterials were not thrombogenic and did not induce hemolysis (Figures 1(a)-(c)). The stability of the platelet count was confirmed using the washed platelets (Figure 2). In addition, we measured absorbance at $540 \mathrm{~nm}$ in diluted whole blood supernatant in order to assess the release of hemoglobin from damaged erythrocytes. Figure 1(d) shows that, even if the hemolysis rates of TWIP steel and pure Fe were slightly higher compared to that of L605 alloy, the three metals did not induce significant hemolysis according to the ASTM F756-08 standard (hemolysis rate below 5\%) [33]. This proved to be in agreement with previous studies showing the low hemolysis rates induced by pure Fe as well as by Fe-3.3 wt.\% Mn and Fe-35 wt.\% Mn alloys [18] [19] [34] [35]. It is worth noting that the mean hemolysis induced by the WE43 Mg alloy was $8.9 \%$. This observation confirmed the results obtained in several studies demonstrating that $\mathrm{Mg}$ alloys displayed hemolysis rates close to [36] or higher [20] [37] [38] [39] [40] than 5\%. Importantly, pure Mg was shown to induce a very high hemolysis rate, estimated at $37 \%$ [34]. The high hemolysis rate of pure $\mathrm{Mg}$ and several of its alloys may be accounted for by the fast corrosion rate of $\mathrm{Mg}$ associated with a release of $\mathrm{Mg}^{2+}$ ions, as well as an essential $\mathrm{pH}$ variation [20] [40]. In another study, the corrosion of pure Fe did not induce significant $\mathrm{pH}$ value changes, which possibly explains why it does not affect hemolysis [41].

Platelet activation resulting from interaction with artificial surfaces is a second 


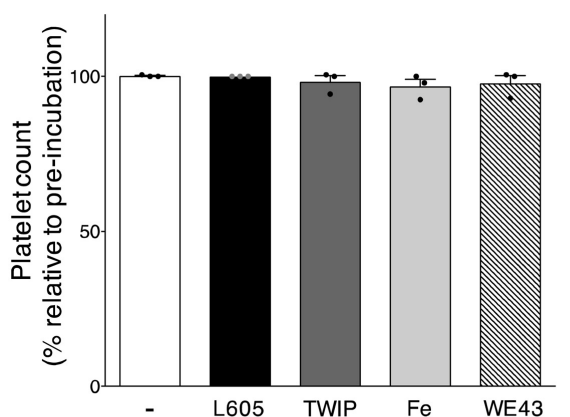

(a)

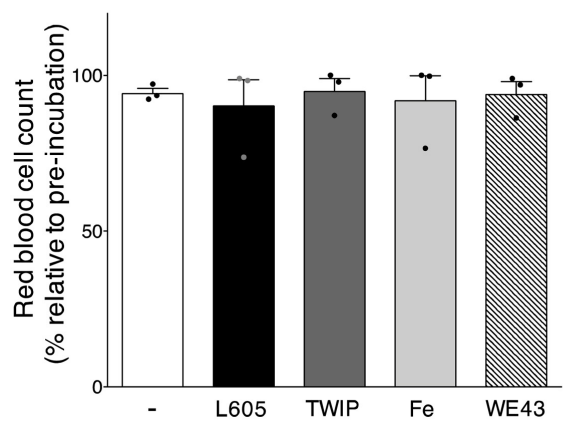

(c)

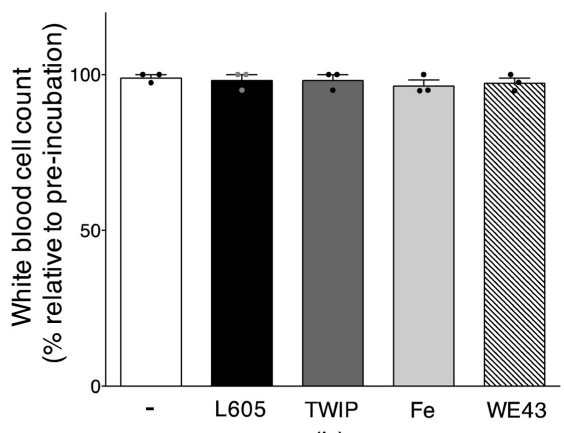

(b)

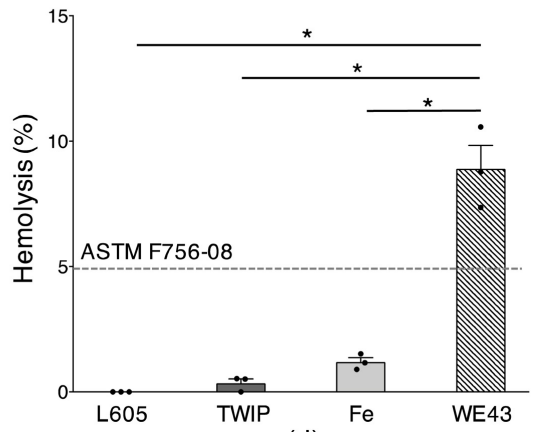

(d)

Figure 1. Blood cell count in total blood and hemolysis rate. (a), (b), and (c) L605 alloy, TWIP steel, pure Fe, and WE43 alloy were dipped into total blood for 1 hour at $37^{\circ} \mathrm{C}$. Blood with no metallic treatment was used as the negative control (-). Platelets, white blood cells, and red blood cells were counted before and after metallic immersion, and the percentage of cells recovered after incubation was calculated. (d) Metallic specimens were dipped in diluted human blood for 1 hour. Following centrifugation, the optical density of the supernatant was measured at $540 \mathrm{~nm}$, and the hemolysis rate was calculated. A hemolysis rate under 5\% (ASTM F756-08) represents a criterion for excellent blood compatibility. The results were expressed as mean $\% \pm$ SEM. The data underwent a one-way analysis of variance (ANOVA) and Tukey's multiple comparison test. * indicates values statistically different with $\mathrm{P}<0.05, \mathrm{n}=3$.

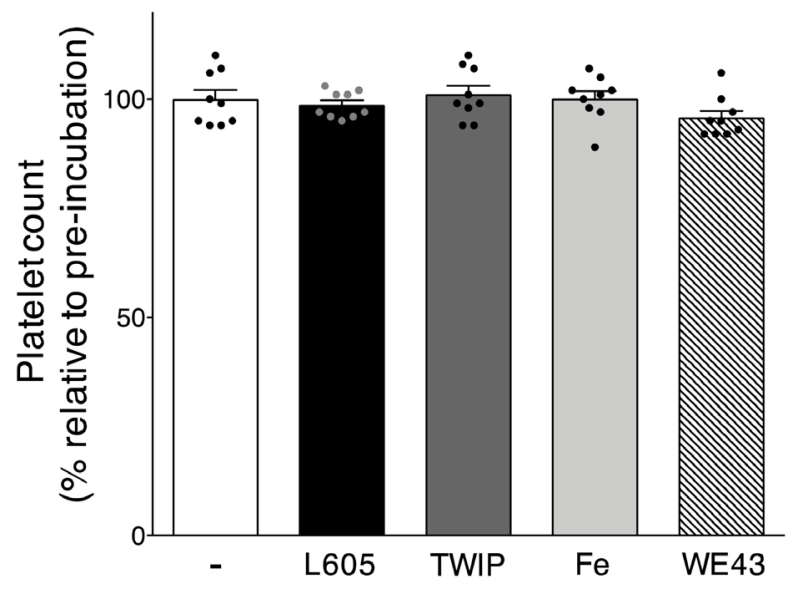

Figure 2. Isolated platelet count. Platelets were isolated and set at a final concentration of $2.5 \times 10^{5}$ platelets/ $\mu \mathrm{l}$. After immersion of the metallic specimens for 1 hour at $37^{\circ} \mathrm{C}$, platelets were counted, and the percentage of platelets recovered after incubation was calculated. Platelets with no metallic treatment were used as the negative control (-). Results were expressed as mean $\% \pm \mathrm{SEM}, \mathrm{n}=9$. 
essential indication of blood incompatibility, as it may lead to thrombotic complications under in vivo conditions [7]. According to ISO-10993-4, platelet activation can be assessed by measuring activated $\alpha \mathrm{IIb} \beta 3$, along with the presence of $\mathrm{CD} 62 \mathrm{P}$ at the platelet surface, by means of flow cytometry [42]. Platelets were incubated for 1 hour with the metals prior to treatment using different thrombin concentrations. As expected, thrombin dose-dependently increased PAC-1 binding and CD62P surface exposure in platelets not previously incubated with metal. While L605 alloy did not affect platelet response upon thrombin stimulation, PAC-1 binding and CD62P exposure were drastically reduced in the presence of TWIP steel, pure Fe, and WE43 alloy (Figure 3(a) and Figure 3(b)). This observation suggests that the three resorbable scaffolds were able to display anti-thrombogenic properties in vitro. Pure $\mathrm{Fe}$ exhibited the same effect as TWIP steel, which implies that Fe itself is likely to be responsible for the TWIP

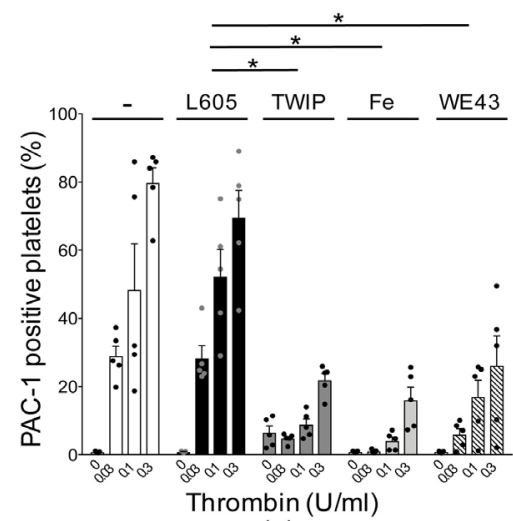

(a)

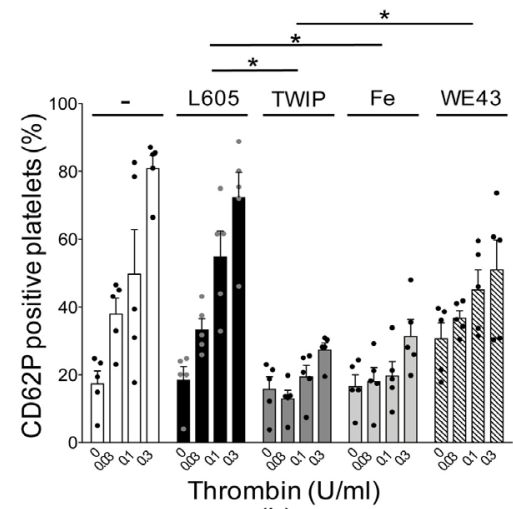

(b)

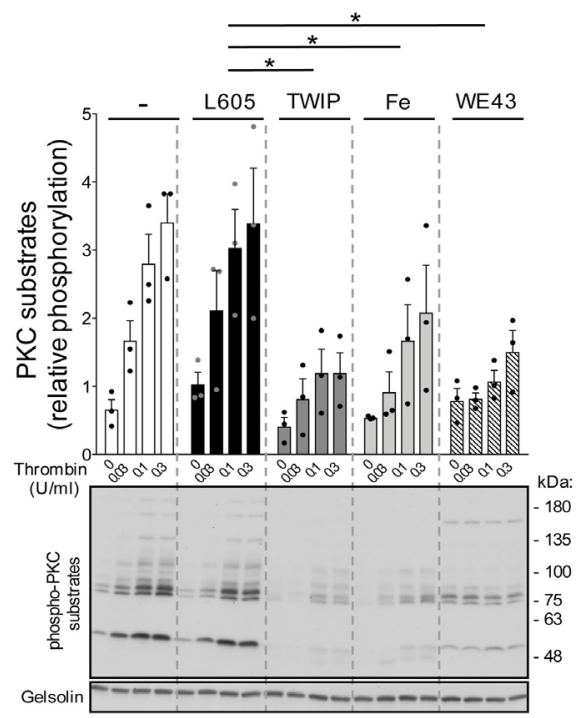

(c)

Figure 3. Platelet activation. Metallic specimens were immersed in washed platelets for 1 hour at $37^{\circ} \mathrm{C}$. Platelets with no metallic treatment were used as the negative control (-). ((a) and (b)) Platelets were stimulated with thrombin at the indicated concentrations for 2 mins at $37^{\circ} \mathrm{C}$. Binding of PAC-1 and surface exposure of CD62P were quantified by flow cytometry $(n=5)$. (c) Platelets were stimulated with thrombin at the indicated concentrations for $2 \mathrm{mins}$ at $37^{\circ} \mathrm{C}$, and proteins were extracted. The relative phosphorylation of the PKC substrates was analyzed with Western blotting $(\mathrm{n}=3)$. Gelsolin was used as the loading control. The results are expressed as mean \pm SEM. The data underwent a two-way ANOVA and Tukey's multiple comparison test. * indicates values statistically different with $\mathrm{P}<0.05$. 
steel-induced antithrombogenic effect. Since the effects of thrombin on platelets are mediated, at least to some extent, through the activation of protein kinase $\mathrm{C}$ (PKC) [43], we performed a Western blot analysis of PKC phosphorylated substrates using protein extracts from platelets treated as described above. In line with our previous results, Figure 3(c) shows that the increased phosphorylation state of the PKC substrates in response to increasing thrombin doses was not affected by L605 alloy, whereas it was significantly reduced in the presence of TWIP steel, pure Fe, and WE43 alloy. Moreover, the unchanged platelet count measured following the metallic samples' immersion in washed plateletsfor 1 hour indicated that the diminution of CD62P exposure, PAC-1 binding, and phosphorylation state of PKC substrates were not due to a decreased platelet number but rather to a real change in platelet activation. This study is the first to describe $\mathrm{CD} 62 \mathrm{P}$, active $\alpha \mathrm{IIb} \beta 3$, and the phosphorylation state of PKC substrates following incubation of a Fe-based metallic sample in washed platelets. Platelet adhesion, shape change, and spreading of pseudopodia-like structures also reflected platelet activation [18] [44]. As previously shown, platelets can adhere to pure Fe or Fe-3.3 wt.\% Mn alloy but conserve a normal round shape with only a few pseudopodia-like structures, indicating no induction of thrombogenicity [19] [34] [35]. A lower platelet reactivity was described following immersion of stents composed of $\mathrm{Fe}-35$ wt.\% Mn alloy in a model of circulating porcine blood, as compared to stainless steel used as reference material. In the latter study, the Fe-35 wt.\% Mnalloy stent decreased platelet adhesion, secretion of $\beta$-thromboglobulin (a marker of platelet activation), and thrombin generation. It has been suggested that the decreased platelet adhesion resulted from the formation of large amounts of corrosion products (oxide layer) on the surface of the Fe-35 wt.\% Mn alloy, rendering the surface nonadherent [18]. We, therefore, investigated whether platelet activation inhibition was due to a direct contact between TWIP steel and platelets or if it resulted from the production of corrosion products released into the incubation medium. To test this, platelets were incubated for 1 hour with a TWIP steel-conditioned medium. We found that the effect of conditioned medium on platelet activation reproduced the effect of direct contact with the metal in regard to both PAC-1 (Figure 4(a)) and CD62P (Figure 4(b)), indicating that TWIP steel corrosion might release components counteracting platelet activation. Moreover, this observation supported the fact that the decrease in platelet activation did not result from a modified metal surface. Fe corrosion produces $\mathrm{Fe}^{2+}$ and $\mathrm{OH}^{-}$, which react to form $\mathrm{Fe}(\mathrm{OH})_{2}$. This is easily oxidized to $\mathrm{Fe}(\mathrm{OH})_{3}$ [45]. We found $\mathrm{Fe}^{2+}(1.3 \pm 0.2 \mathrm{mg} / \mathrm{L})$ and $\mathrm{Fe}^{3+}(13.2 \pm$ $1.4 \mathrm{mg} / \mathrm{L}$ ) in the TWIP steel-conditioned medium, suggesting that $\mathrm{Fe}^{3+}$ might contribute to the inhibition of platelet activation. This was surprising, given that some studies have highlighted the thrombogenic effect of $\mathrm{Fe}^{3+}$-containing molecules in vivo through a mechanism involving induction of oxidative stress in platelets [46] [47]. Moreover, $\mathrm{FeCl}_{3}$ is currently being used in animal models to induce thrombosis in the arteries. Of note is, however, that $\mathrm{FeCl}_{3}$-induced 


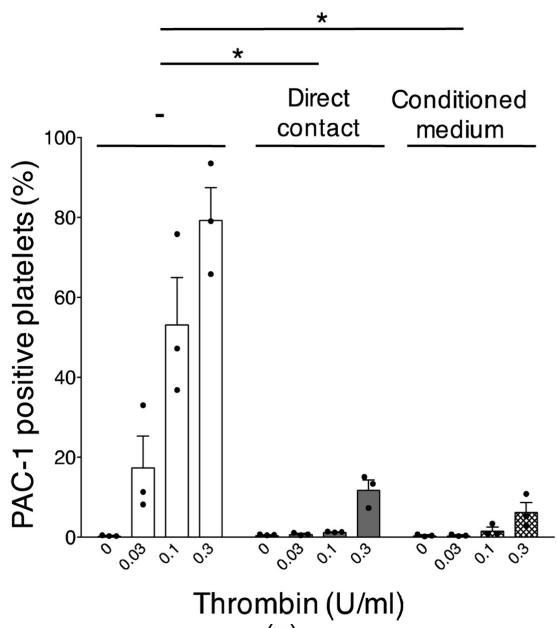

(a)

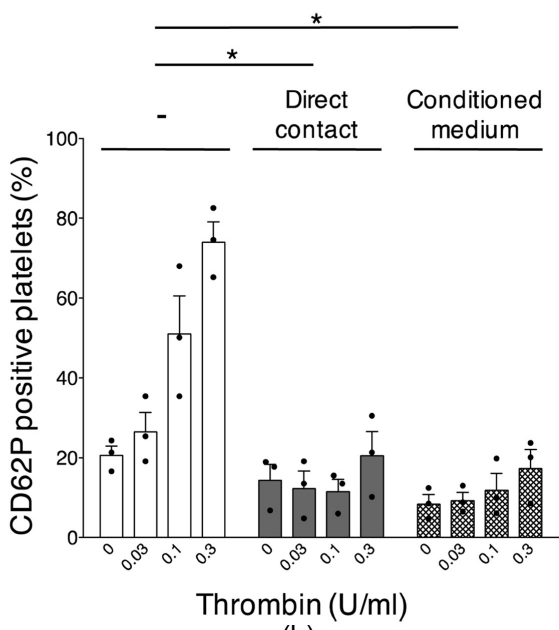

(b)

Figure 4. Effect of TWIP steel-conditioned medium on platelet activation. The conditioned medium was prepared by immersion of TWIP steel into a modified Tyrode's buffer for 1 hour at $37^{\circ} \mathrm{C}$. Washed platelets were suspended in the conditioned medium at a concentration of $2.5 \times 10^{5}$ platelets $/ \mu \mathrm{L}$. Platelets were stimulated with thrombin at the indicated concentrations for $2 \mathrm{~min}$ at $37^{\circ} \mathrm{C}$. Binding of PAC-1 (a) and surface exposure of $\mathrm{CD} 62 \mathrm{P}$ (b) were quantified using flow cytometry. The results were compared with those obtained with platelets in direct contact with the metal or without metallic incubation (-). The results were expressed as mean $\% \pm$ SEM. The data underwent a two-way ANOVA and Tukey's multiple comparison test. ${ }^{*}$ indicates values statistically different with $\mathrm{P}<$ $0.05, \mathrm{n}=3$.

thrombosis relies on complex multifaceted and incompletely elucidated mechanisms. It was historically accepted that spherical bodies filled with $\mathrm{Fe}^{3+}$ would bud from endothelial cells and support platelet adhesion, triggering their aggregation [48]. Recently, however, several studies have reported that plasma proteins and red blood cells contribute to platelet aggregation, owing to that their negatively-charged proteins bind to positively-charged iron species [49] [50] [51]. Therefore, working on isolated platelets might explain the lack of $\mathrm{Fe}^{3+}$-induced platelet activation in our study. In contrast, an antithrombotic effect of $\mathrm{Fe}^{3+}$ was previously described by Miron et al., in accordance with our findings. In this latter study, the addition of nonphysiological concentrations of ferric nitrate $\left(\mathrm{Fe}\left(\mathrm{NO}_{3}\right)_{3}\right)$ to human platelets was shown to activate the ectonucleoside triphosphate phosphohydrolase responsible for the hydrolysis of ADP, as well as the 5'-nucleotidase, responsible for the hydrolysis of AMP into adenosine. These two enzymes led to ADP level depletion and, therefore, decreased platelet activation [52].

\section{Conclusion}

Our study showed the relative in vitro hemocompatibility of new bioresorbable TWIP steel compared to traditional stent materials. Unlike WE43 alloy, TWIP steel does not induce significant hemolysis. Moreover, it inhibits platelet activation compared to L605 alloy, suggesting that TWIP steel presents antithrombotic 
properties. $\mathrm{Fe}^{3+}$ released as a corrosion product could be responsible for this effect. Our results indicated that TWIP steel is a good potential candidate for cardiovascular stent applications. However, as in vitro tests are unable to reproduce physiological environments, in vivo compatibility evaluation is necessary to confirm our encouraging findings.

\section{Acknowledgements}

The authors would like to thank Marc Sinnaeve and Alban Maton for metallic specimen preparation, Ronny Santoro for the ICP and colorimetric tests, and Frédéric Van Wonterghem for the preparation of electropolishing solutions. This work was supported by grants from Action de Recherche Concertée de la Communauté Wallonie-Bruxelles, Belgium (ARC 15/20-066) and unrestricted grants from Astra Zeneca.S.L. was supported by the Fonds National de la Recherche Scientifique et Médicale (FNRS, Belgium). M.O., A.T., and S.R. were supported by a FRIA fellowship (FNRS, Belgium). S.H. works as a research associate at FNRS, Belgium.

\section{Conflicts of Interest}

The authors declare no conflicts of interest regarding the publication of this paper.

\section{References}

[1] Libby, P., Ridker, P.M. and Hansson, G.K. (2011) Progress and Challenges in Translating the Biology of Atherosclerosis. Nature, 473, 317-325.

https://doi.org/10.1038/nature10146

[2] Corban, M.T., Lerman, L.O. and Lerman, A. (2019) Endothelial Dysfunction. Arteriosclerosis, Thrombosis, and Vascular Biology, 39, 1272-1274.

https://doi.org/10.1161/ATVBAHA.119.312836

[3] Maddox, T.M., Stanislawski, M.A., Grunwald, G.K., Bradley, S.M., Ho, P.M., Tsai, T.T., Patel, M.R., Sandhu, A., Valle, J., Magid, D.J., Leon, B., Bhatt, D.L., Fihn, S.D. and Rumsfeld, J.S. (2014) Nonobstructive Coronary Artery Disease and Risk of Myocardial Infarction. JAMA, 312, 1754-1763. https://doi.org/10.1001/jama.2014.14681

[4] Du, F. and Zhou, J. (2018) Vascular Intervention: From Angioplasty to Bioresorbable Vascular Scaffold. Advances in Experimental Medicine and Biology, 1097, 181-189. https://doi.org/10.1007/978-3-319-96445-4_9

[5] Iqbal, J., Gunn, J. and Serruys, P.W. (2013) Coronary Stents: Historical Development, Current Status and Future Directions. British Medical Bulletin, 106, 193-211. https://doi.org/10.1093/bmb/ldt009

[6] Borhani, S., Hassanajili, S., Ahmadi Tafti, S.H. and Rabbani, S. (2018) Cardiovascular Stents: Overview, Evolution, and Next Generation. Progress in Biomaterials, 7, 175-205. https://doi.org/10.1007/s40204-018-0097-y

[7] Weber, M., Steinle, H., Golombek, S., Hann, L., Schlensak, C., Wendel, H.P. and Avci-Adali, M. (2018) Blood-Contacting Biomaterials: In Vitro Evaluation of the Hemocompatibility. Frontiers in Bioengineering and Biotechnology, 6, 99. https://doi.org/10.3389/fbioe.2018.00099 
[8] Yen, J.H., Chen, S.F., Chern, M.K. and Lu, P.C. (2014) The Effect of Turbulent Viscous Shear Stress on Red Blood Cell Hemolysis. Journal of Artificial Organs, 17, 178-185. https://doi.org/10.1007/s10047-014-0755-3

[9] Merle, N.S., Grunenwald, A., Figueres, M.L., Chauvet, S., Daugan, M., Knockaert, S., Robe-Rybkine, T., Noe, R., May, O., Frimat, M., Brinkman, N., Gentinetta, T., Miescher, S., Houillier, P., Legros, V., Gonnet, F., Blanc-Brude, O.P., Rabant, M., Daniel, R., Dimitrov, J.D. and Roumenina, L.T. (2018) Characterization of Renal Injury and Inflammation in an Experimental Model of Intravascular Hemolysis. Frontiers in Immunology, 9, 179. https://doi.org/10.3389/fimmu.2018.00179

[10] Rossaint, J., Margraf, A. and Zarbock, A. (2018) Role of Platelets in Leukocyte Recruitment and Resolution of Inflammation. Frontiers in Immunology, 9, 2712. https://doi.org/10.3389/fimmu.2018.02712

[11] Etulain, J. and Schattner, M. (2014) Glycobiology of Platelet-Endothelial Cell Interactions. Glycobiology, 24, 1252-1259. https://doi.org/10.1093/glycob/cwu056

[12] Diamond, S.L. (2016) Systems Analysis of Thrombus Formation. Circulation Research, 118, 1348-1362. https://doi.org/10.1161/CIRCRESAHA.115.306824

[13] Jaffer, I.H., Fredenburgh, J.C., Hirsh, J. and Weitz, J.I. (2015) Medical Device-Induced Thrombosis: What Causes It and How Can We Prevent It? Journal of Thrombosis and Haemostasis, 13, S72-S81. https://doi.org/10.1111/jth.12961

[14] Swieringa, F., Spronk, H.M.H., Heemskerk, J.W.M. and van der Meijden, P.E.J. (2018) Integrating Platelet and Coagulation Activation in Fibrin Clot Formation. Research and Practice in Thrombosis and Haemostasis, 2, 450-460. https://doi.org/10.1002/rth2.12107

[15] Dziewierz, A. and Dudek, D. (2018) Current Perspectives on the Role of Bioresorbable Scaffolds in the Management of Coronary Artery Disease. Kardiologia Polska, 76, 1043-1054. https://doi.org/10.5603/KP.a2018.0130

[16] Dave, B. (2016) Bioresorbable Scaffolds: Current Evidences in the Treatment of Coronary Artery Disease. Journal of Clinical and Diagnostic Research, 10, OE01-OE07. https://doi.org/10.7860/JCDR/2016/21915.8429

[17] Moravej, M. and Mantovani, D. (2011) Biodegradable Metals for Cardiovascular Stent Application: Interests and New Opportunities. International Journal of Molecular Sciences, 12, 4250-4270. https://doi.org/10.3390/ijms12074250

[18] Walker, E.K., Nauman, E.A., Allain, J.P. and Stanciu, L.A. (2015) An in Vitro Model for Preclinical Testing of Thrombogenicity of Resorbable Metallic Stents. Journal of Biomedical Materials Research Part A, 103, 2118-2125.

https://doi.org/10.1002/jbm.a.35348

[19] Liu, B. and Zheng, Y.F. (2011) Effects of Alloying Elements (Mn, Co, Al, W, Sn, B, $\mathrm{C}$ and S) on Biodegradability and in Vitro Biocompatibility of Pure Iron. Acta Biomaterialia, 7, 1407-1420. https://doi.org/10.1016/j.actbio.2010.11.001

[20] Liu, Y., Wu, Y., Bian, D., Gao, S., Leeflang, S., Guo, H., Zheng, Y. and Zhou, J. (2017) Study on the Mg-Li-Zn Ternary Alloy System with Improved Mechanical Properties, Good Degradation Performance and Different Responses to Cells. Acta Biomaterialia, 62, 418-433. https://doi.org/10.1016/j.actbio.2017.08.021

[21] Yahata, C. and Mochizuki, A. (2017) Platelet Compatibility of Magnesium Alloys. Materials Science \& Engineering C-Materials for Biological Applications, 78, 1119-1124. https://doi.org/10.1016/j.msec.2017.04.153

[22] Feyerabend, F., Wendel, H.P., Mihailova, B., Heidrich, S., Agha, N.A., Bismayer, U. and Willumeit-Romer, R. (2015) Blood Compatibility of Magnesium and Its Alloys. 
Acta Biomaterialia, 25, 384-394. https://doi.org/10.1016/j.actbio.2015.07.029

[23] Peuster, M., Hesse, C., Schloo, T., Fink, C., Beerbaum, P. and von Schnakenburg, C. (2006) Long-Term Biocompatibility of a Corrodible Peripheral Iron Stent in the Porcine Descending Aorta. Biomaterials, 27, 4955-4962.

https://doi.org/10.1016/j.biomaterials.2006.05.029

[24] Peuster, M., Wohlsein, P., Brugmann, M., Ehlerding, M., Seidler, K., Fink, C., Brauer, H., Fischer, A. and Hausdorf, G. (2001) A Novel Approach to Temporary Stenting: Degradable Cardiovascular Stents Produced from Corrodible Metal-Results 6-18 Months after Implantation into New Zealand White Rabbits. Heart, 86, 563-569. https://doi.org/10.1136/heart.86.5.563

[25] Waksman, R., Pakala, R., Baffour, R., Seabron, R., Hellinga, D. and Tio, F.O. (2008) Short-Term Effects of Biocorrodible Iron Stents in Porcine Coronary Arteries. Journal of Interventional Cardiology, 21, 15-20.

https://doi.org/10.1111/j.1540-8183.2007.00319.x

[26] Haude, M., Erbel, R., Erne, P., Verheye, S., Degen, H., Vermeersch, P., Weissman, N., Prati, F., Bruining, N., Waksman, R. and Koolen, J. (2016) Safety and Performance of the Drug-Eluting Absorbable Metal Scaffold (DREAMS) in Patients with De Novo Coronary Lesions: 3-Year Results of the Prospective, Multicentre, First-in-Man BIOSOLVE-I Trial. EuroIntervention, 12, e160-e166. https://doi.org/10.4244/EIJ-D-15-00371

[27] Sakamoto, A., Jinnouchi, H., Torii, S., Virmani, R. and Finn, A.V. (2018) Understanding the Impact of Stent and Scaffold Material and Strut Design on Coronary Artery Thrombosis from the Basic and Clinical Points of View. Bioengineering (Basel), 5, 71. https://doi.org/10.3390/bioengineering5030071

[28] Sezer, N., Evis, Z., Kayhan, S.M., Tahmasebifar, A. and Koç, M. (2018) Review of Magnesium-Based Biomaterials and Their Applications. Journal of Magnesium and Alloys, 6, 23-43. https://doi.org/10.1016/j.jma.2018.02.003

[29] Idrissi, H., Renard, K., Ryelandt, L., Schryvers, D. and Jacques, P.J. (2010) On the Mechanism of Twin Formation in Fe-Mn-C TWIP Steels. Acta Materialia, 58, 2464-2476. https://doi.org/10.1016/j.actamat.2009.12.032

[30] Renard, K. and Jacques, P.J. (2012) On the Relationship between Work Hardening and Twinning Rate in TWIP Steels. Materials Science and Engineering A, 542, 8-14. https://doi.org/10.1016/j.msea.2012.01.123

[31] De Cooman, B.C., Estrin, Y. and Kim, S.K. (2018) Twinning-Induced Plasticity (TWIP) Steels. Acta Materialia, 142, 283-362. https://doi.org/10.1016/j.actamat.2017.06.046

[32] Goodhead, L.K. and MacMillan, F.M. (2017) Measuring Osmosis and Hemolysis of Red Blood Cells. Advances in Physiology Education, 41, 298-305. https://doi.org/10.1152/advan.00083.2016

[33] ASTM F. F756-08 (2013) Standard Practice for Assessment of Hemolytic Properties of Materials, ASTM Book of Standards. ASTM International, West Conshohocken.

[34] Cheng, J., Liu, B., Wu, Y.H. and Zheng, Y.F. (2013) Comparative in Vitro Study on Pure Metals (Fe, Mn, Mg, Zn and W) as Biodegradable Metals. Journal of Materials Science \& Technology, 29, 619-627. https://doi.org/10.1016/j.jmst.2013.03.019

[35] Huang, T., Cheng, Y. and Zheng, Y. (2016) In Vitro Studies on Silver Implanted Pure Iron by Metal Vapor Vacuum Arc Technique. Colloids and Surfaces B: Biointerfaces, 142, 20-29. https://doi.org/10.1016/j.colsurfb.2016.01.065

[36] Li, M., Cheng, Y., Zheng, Y.F., Zhang, X., Xi, T.F. and Wei, S.C. (2012) Surface Characteristics and Corrosion Behaviour of WE43 Magnesium Alloy Coated by SiC 
Film. Applied Surface Science, 258, 3074-3081. https://doi.org/10.1016/j.apsusc.2011.11.040

[37] Wei, Z., Tian, P., Liu, X. and Zhou, B. (2014) Hemocompatibility and Selective Cell Fate of Polydopamine-Assisted Heparinized PEO/PLLA Composite Coating on Biodegradable AZ31 Alloy. Colloids and Surfaces B: Biointerfaces, 121, 451-460. https://doi.org/10.1016/j.colsurfb.2014.06.036

[38] Zhou, W.R., Zheng, Y.F., Leeflang, M.A. and Zhou, J. (2013) Mechanical Property, Biocorrosion and in Vitro Biocompatibility Evaluations of Mg-Li-(Al)-(RE) Alloys for Future Cardiovascular Stent Application. Acta Biomaterialia, 9, 8488-8498. https://doi.org/10.1016/j.actbio.2013.01.032

[39] Mao, L., Yuan, G., Niu, J., Zong, Y. and Ding, W. (2013) In Vitro Degradation Behavior and Biocompatibility of Mg-Nd-Zn-Zr Alloy by Hydrofluoric Acid Treatment. Materials Science \& Engineering C-Materials for Biological Applications, 33, 242-250. https://doi.org/10.1016/j.msec.2012.08.036

[40] Gu, X., Zheng, Y., Cheng, Y., Zhong, S. and Xi, T. (2009) In Vitro Corrosion and Biocompatibility of Binary Magnesium Alloys. Biomaterials, 30, 484-498.

https://doi.org/10.1016/j.biomaterials.2008.10.021

[41] Huang, T., Cheng, J., Bian, D. and Zheng, Y. (2016) Fe-Au and Fe-Ag Composites as Candidates for Biodegradable Stent Materials. Journal of Biomedical Materials Research Part B: Applied Biomaterials, 104, 225-240. https://doi.org/10.1002/jbm.b.33389

[42] ISO 10993 (2002) Biological Evaluation of Medical Devices-Part 4: Selection of Tests for Interactions with Blood. International Organization for Standardization, Genève.

[43] Moore, S.F., Hunter, R.W. and Hers, I. (2014) Protein Kinase C and P2Y12 Take Center Stage in Thrombin-Mediated Activation of Mammalian Target of Rapamycin Complex 1 in Human Platelets. Journal of Thrombosis and Haemostasis, 12, 748-760. https://doi.org/10.1111/jth.12552

[44] Huang, T., Cheng, J. and Zheng, Y.F. (2014) In Vitro Degradation and Biocompatibility of Fe-Pd and Fe-Pt Composites Fabricated by Spark Plasma Sintering. Materials Science \& Engineering C-Materials for Biological Applications, 35, 43-53. https://doi.org/10.1016/j.msec.2013.10.023

[45] Hermawan, H., Purnama, A., Dube, D., Couet, J. and Mantovani, D. (2010) Fe-Mn Alloys for Metallic Biodegradable Stents: Degradation and Cell Viability Studies. Acta Biomaterialia, 6, 1852-1860. https://doi.org/10.1016/j.actbio.2009.11.025

[46] Nemmar, A., Beegam, S., Yuvaraju, P., Yasin, J., Tariq, S., Attoub, S. and Ali, B.H. (2016) Ultrasmall Superparamagnetic Iron Oxide Nanoparticles Acutely Promote Thrombosis and Cardiac Oxidative Stress and DNA Damage in Mice. Particle and Fibre Toxicology, 13, 22. https://doi.org/10.1186/s12989-016-0132-x

[47] Rooyakkers, T.M., Stroes, E.S., Kooistra, M.P., van Faassen, E.E., Hider, R.C., Rabelink, T.J. and Marx, J.J. (2002) Ferric Saccharate Induces Oxygen Radical Stress and Endothelial Dysfunction in Vivo. European Journal of Clinical Investigation, 32, 9-16. https://doi.org/10.1046/j.1365-2362.2002.0320s1009.x

[48] Eckly, A., Hechler, B., Freund, M., Zerr, M., Cazenave, J.P., Lanza, F., Mangin, P.H. and Gachet, C. (2011) Mechanisms Underlying $\mathrm{FeCl}_{3}$-Induced Arterial Thrombosis. Journal of Thrombosis and Haemostasis, 9, 779-789. https://doi.org/10.1111/j.1538-7836.2011.04218.x

[49] Ciciliano, J.C., Sakurai, Y., Myers, D.R., Fay, M.E., Hechler, B., Meeks, S., Li, R., Dixon, J.B., Lyon, L.A., Gachet, C. and Lam, W.A. (2015) Resolving the Multifa- 
ceted Mechanisms of the Ferric Chloride Thrombosis Model Using an Interdisciplinary Microfluidic Approach. Blood, 126, 817-824.

https://doi.org/10.1182/blood-2015-02-628594

[50] Schoenwaelder, S.M. and Jackson, S.P. (2015) Ferric Chloride Thrombosis Model: Unraveling the Vascular Effects of a Highly Corrosive Oxidant. Blood, 126, 2652-2653. https://doi.org/10.1182/blood-2015-09-668384

[51] Barr, J.D., Chauhan, A.K., Schaeffer, G.V., Hansen, J.K. and Motto, D.G. (2013) Red Blood Cells Mediate the Onset of Thrombosis in the Ferric Chloride Murine Model. Blood, 121, 3733-3741. https://doi.org/10.1182/blood-2012-11-468983

[52] Miron, V.R., Bauermann, L., Morsch, A.L., Zanin, R.F., Correa, M., da Silva, A.C., Mazzanti, C., Morsch, V.M., Lunkes, G.I. and Schetinger, M.R. (2007) Enhanced NTPDase and 5'-Nucleotidase Activities in Diabetes Mellitus and Iron-Overload Model. Molecular and Cellular Biochemistry, 298, 101-107.

https://doi.org/10.1007/s11010-006-9357-6 